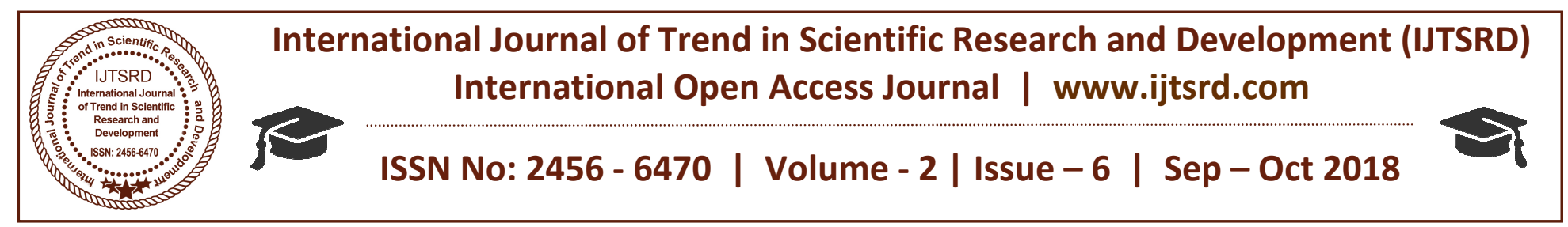

\title{
Crack and Object Detection in Pipeline using Inspection Robot
}

\author{
Hemavathi. $\mathbf{R}^{1}$, Pushpalatha B A ${ }^{2}$ \\ ${ }^{1}$ Assistant Professor, ${ }^{2}$ PG Scholar(C\&I) \\ University Visvesvaraya College of Engineering, Bengaluru, Karnataka, India
}

\begin{abstract}
Pipelines are important means of transportation of gas, water, fuel oils, etc. in various fields. The transportation loss occurs due to aging, corrosion, obstacles, crack and mechanical faults in the pipeline. The lifetime of pipeline can be increased by regular inspection of pipeline and recognizing the cracks, damages and faults in the pipeline and ensuring proper maintenance of faults. This helps in preventing transportation loss and maintaining profitable gross. Thus, this paper aims to propose an autonomous robot used for in-pipe inspection which provides easy way of detecting crack and obstacle inside the pipe.
\end{abstract}

The mechanical model of the pipe inspection robot was design according to the requirements of physical size of the pipe. The basic design of inspection robot consists of robot body and DC motors with the rating of $9 \mathrm{~V}$ and $35 \mathrm{rpm}$ are attached to the wheels to move the robot forward and backward. The electronic circuit is developed, consisting of an $\mathrm{H}$ Bridge and Arduino Uno which in turn controls the entire connection of DC motors and sensors. The robot allows for detection of cracks and obstacles inside the pipe and also allows us to communicate with it through serial communication.

Keyword: pipeline inspection robot, crack, object obstacle, Arduino, LDR, IR, motor drivers

\section{INTRODUCTION}

Different industries equipped large pipelines to fulfil the requirements of the work. Pipelines connect different parts and helps in transporting various kinds of things such as gas, water, fuel oils etc. The maintenance of these pipelines is very tedious job and involves more human labour. The main motto of developing robots is to reduce human interaction with the work. Hence, the growth of robots is tremendous in this technologically advanced era. Robots are helps in eliminate the human factor from labour intensive or dangerous and inaccessible work environment. The use of robots is very common in this age of automation and robots are exclusively used by manufacturing industries. Since the dawn of industries, pipelines are tools for transporting oils, gases and other fluids. Many defects occur in pipelines and a majority of them are caused by aging, corrosion, cracks, blocking and mechanical disasters which harm both human life and environment equally. Thus, the inspection of pipes is extremely important for improving the reliability and security of the industries. Currently, one of the most viable solutions for inspection of pipelines is robots. Now there are many ways of inspecting pipes such as X-rays, magnetic particle type inspection method etc., but these methods do not give a full proper internal inspection of pipes. Hence this paper involves in developinga prototype of inspection robot which provides an easy method of detecting major cracks and obstacle inside the pipeline. This pipe inspection robot also aims at removing human factor from labour intensive and dangerous work, thereby reducing the number of accidents that happen due to the lack of regular inspection.

\section{METHODOLOGY}

The design of pipeline inspection robot needs the robot anatomy and sensors to inspect the factors inside the pipe. The robot anatomy usually includes the chassis, wheels and motors to drive it. There are varieties of types of sensors which available to detect and inspect the factors like major crack and object obstacle. One should select the sensors which are robust, economical and more sensible.

Here, Light Dependent Resistor (LDR) and Infrared (IR) sensors are used to detect crack and obstacle inside the pipeline. Arduino is most suitable controller 
which provides simple perfect programming environment for beginners. It is very flexible controller used by advanced users. Motor drivers are used to drive the motors. It includes L293D and 4channel relay for driving the motors. There are three motors for wheels and one motor for drill bit. The crack and object obstacle are detected by the robot by incorporating the above mentioned components. The status of the crack and obstacle can be displayed on PC. The proposed prototype of robot here is used for 6- 8 inches diameter pipes. The block diagram of the inspection robot is shown in figure 1.

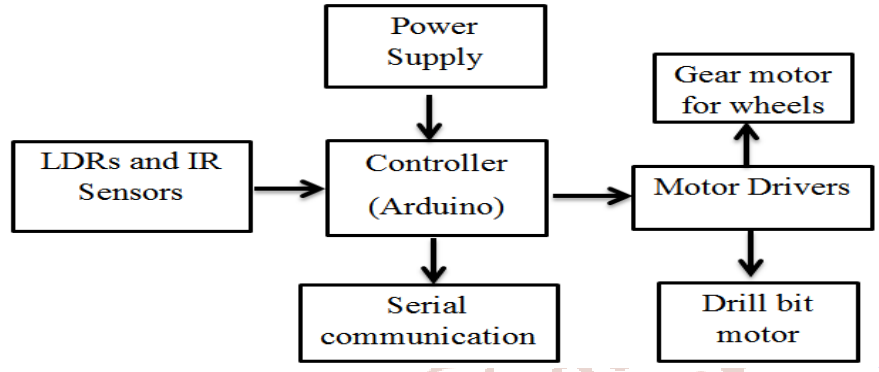

Figure 1: Block diagram of the pipeline inspection robot

\section{HARDWARE SYSTEM}

The developed inspection robot has Light emitting resistor (LDR) and infrared (IR) sensors for identifying major cracks and object obstacles. The other associate components are Arduino, motor divers, DC motors.

\section{A. LDR}

There are two LDRs mounted on robot to cover the major portion of inside surface of the pipe. When light falls on LDR through the pipe cracks, its resistance changes in turn results in voltage change. This voltage value is examined and sends to Arduino as ADC value. The circuit diagram of LDR is shown in figure 2.

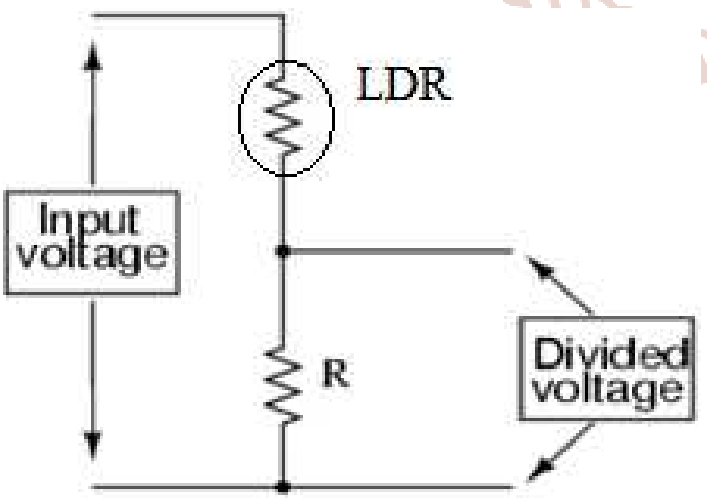

Figure 2: Circuit diagram of LDR

\section{B. IR}

IR senor is used to detect object inside the pipeline. IR is a general purpose proximity sensor. The module consists of IR emitter and receiver pair. Whenever the light falls on object, the light gets reflected back to the sensor which in turn on the sensor. The object detection by IR sensor is shown in figure 3 .

\section{IR Transmitter}
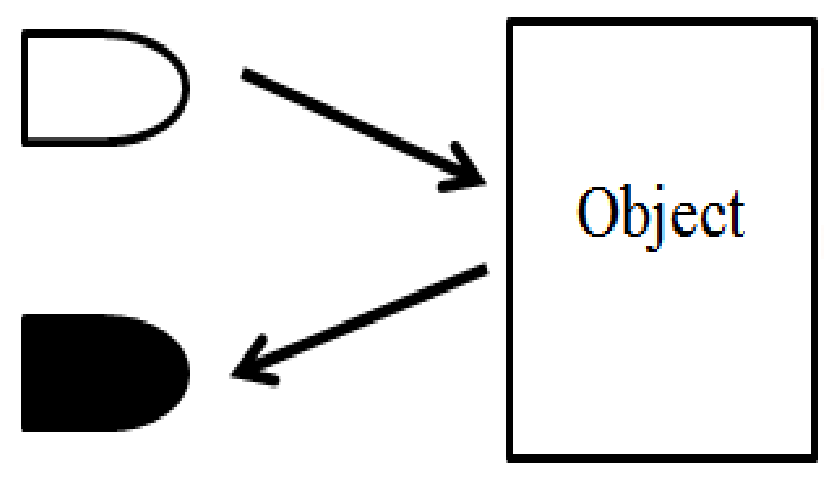

\section{IR Receiver}

Figure 3: Object detection by IR sensor

\section{ARDUINO}

Arduino UNO is a microcontroller board based on the Microchip ATmega328P used here. The board has 14 digital pins and 6 analog pins. The programming has done in Arduino IDE software. It provides various ways of communication with PC. The ATmega328 has UART TTL serial communication, which is available on digital pins $0(\mathrm{RX})$ and $1(\mathrm{TX})$. The Arduino IDE software has serial monitor which allows sending or received data from the Arduino board.

\section{MOTOR DRIVERS}

L293D and 4- Channel relay are used as motor drivers. These motor drivers allow DC motor to drive/run in either direction, which is very important movement of robot in forward/ reverse direction.

\section{E. DC Motors}

Geared DC motors are used for movement of the robot. Three DC motors have been used for movement and one more motor is used for drill bit. $9 \mathrm{~V}$ and $35 \mathrm{rpm}$ geared motors were chosen here.

\section{SOFTWARE IMPLEMENTATION}

Arduino IDE is a software system which is an open source computer hardware and software. The programme has been written in $\mathrm{C}$ in Arduino IDE. The flow chart of the code is shown in figure 4 . The characters ' $a$ ', 'b' and ' $c$ ' have to enter in serial monitor. 


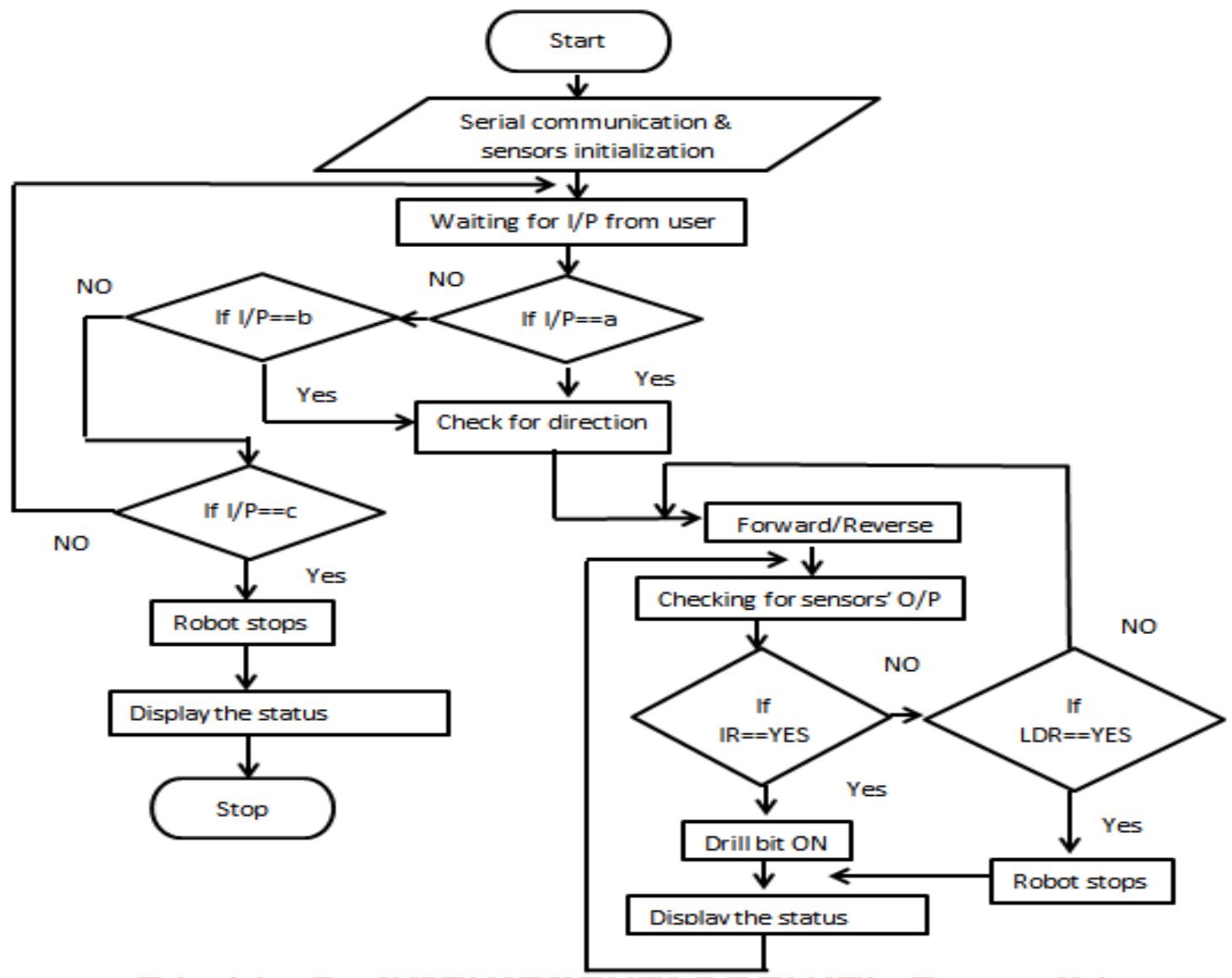

Figure 4: Flowchart of code

\section{APPLICATIONS}

The applications of the developed inspection robot are mentioned as follows:

1. Conventional power plant

2. Refineries

3. Chemical and petro chemical plants

4. Domestic water supply pipelines

5. Natural gas pipelines and so on.

\section{SIMULATION AND RESULTS}

The simulation of each of the sensors is done separately to understand the behaviour and response of particular sensor. And combining all the blocks, the final simulation has done.

\section{A. SIMULATION OF LDR SENSOR}

The interface of LDR with Arduino has been done using Lab VIEW (Visual programming language by national instruments) through Maker hub. The block diagram and the front panel are shown in figure 5, figure 6 and figure 7 .

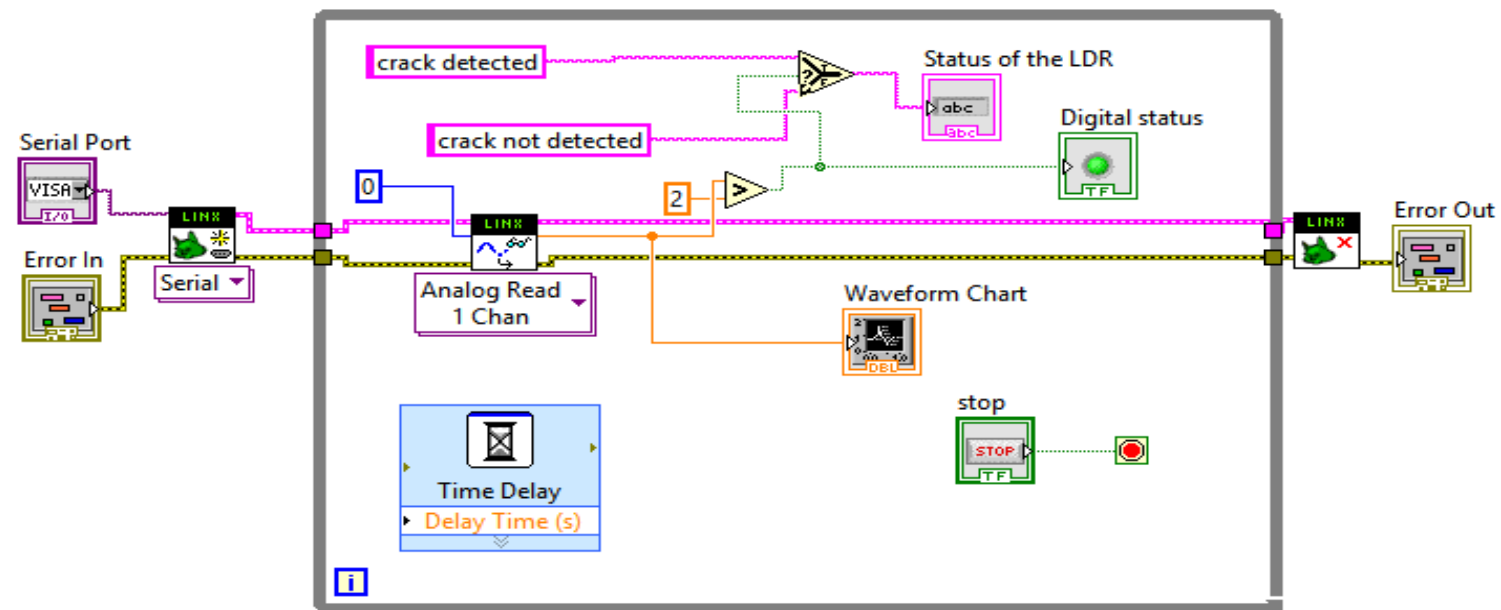

Figure 5: Block diagram of LDR interfacing with Lab VIEW 
International Journal of Trend in Scientific Research and Development (IJTSRD) ISSN: 2456-6470

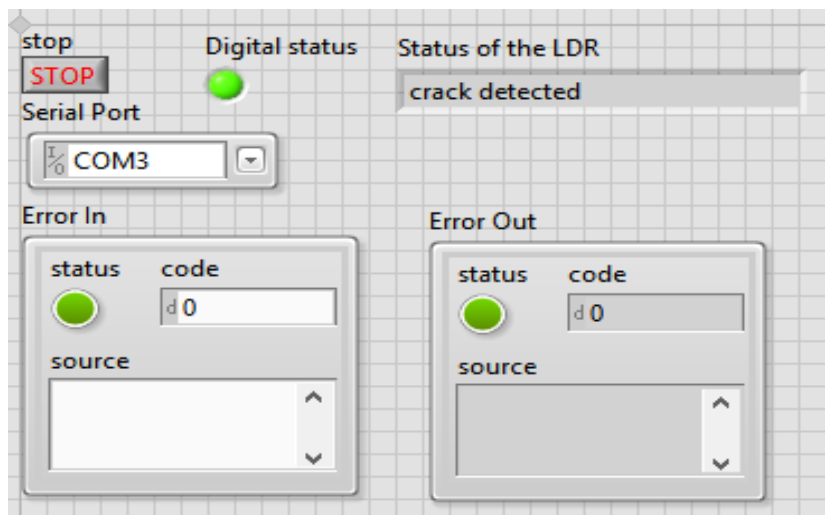

Figure 6: Front panel which show ON status of the LDR

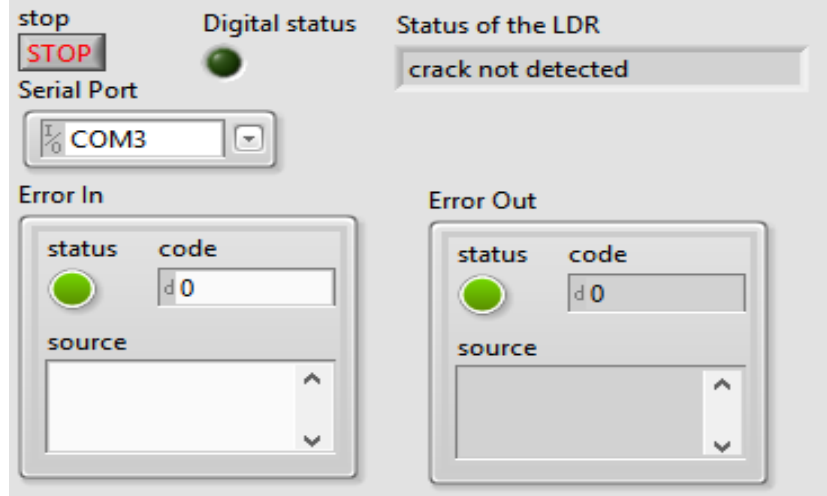

Figure 7: Front panels which show OFF status of the LDR

\section{B. SIMULATION OF IR SENSOR}

The block diagram and front panel in Lab VIEW for interfacing IR with Arduino are shown in figure 8, figure 9 and figure 10 .

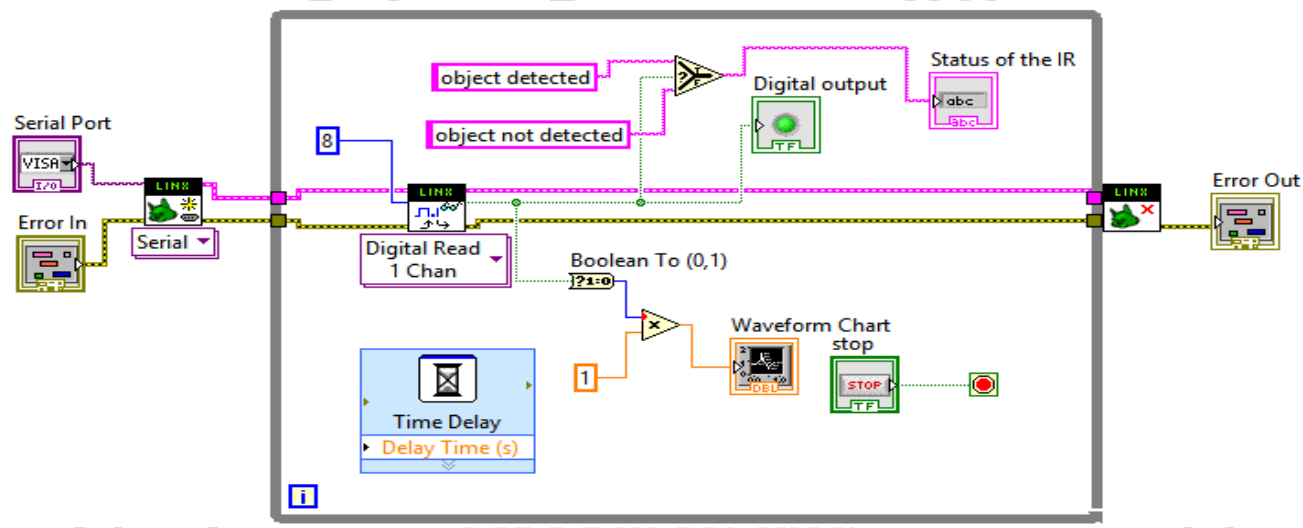

Figure 8: Block diagram for interfacing IR with Arduino

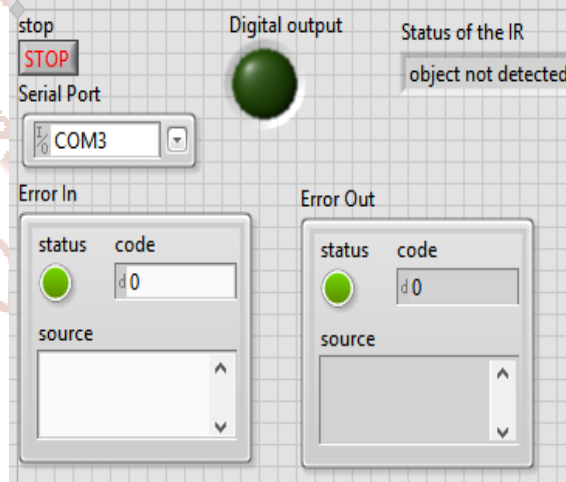

Figure 9: Front panel showing OFF status of IR sensor's output

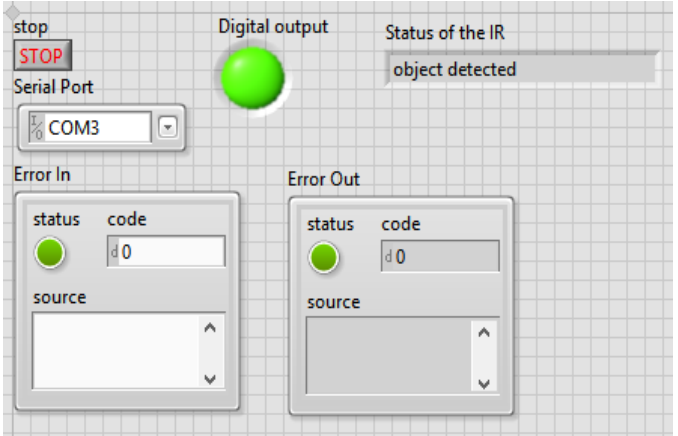

Figure 10: Front panel showing ON status of IR sensor's output 


\section{RESULTS IN ARDUINO'S SERIAL MONITOR}

The results were obtained by running the robot and the status was viewed on PC through serial monitor. The following were the images obtained showing the status of crack and object obstacle in pipeline.

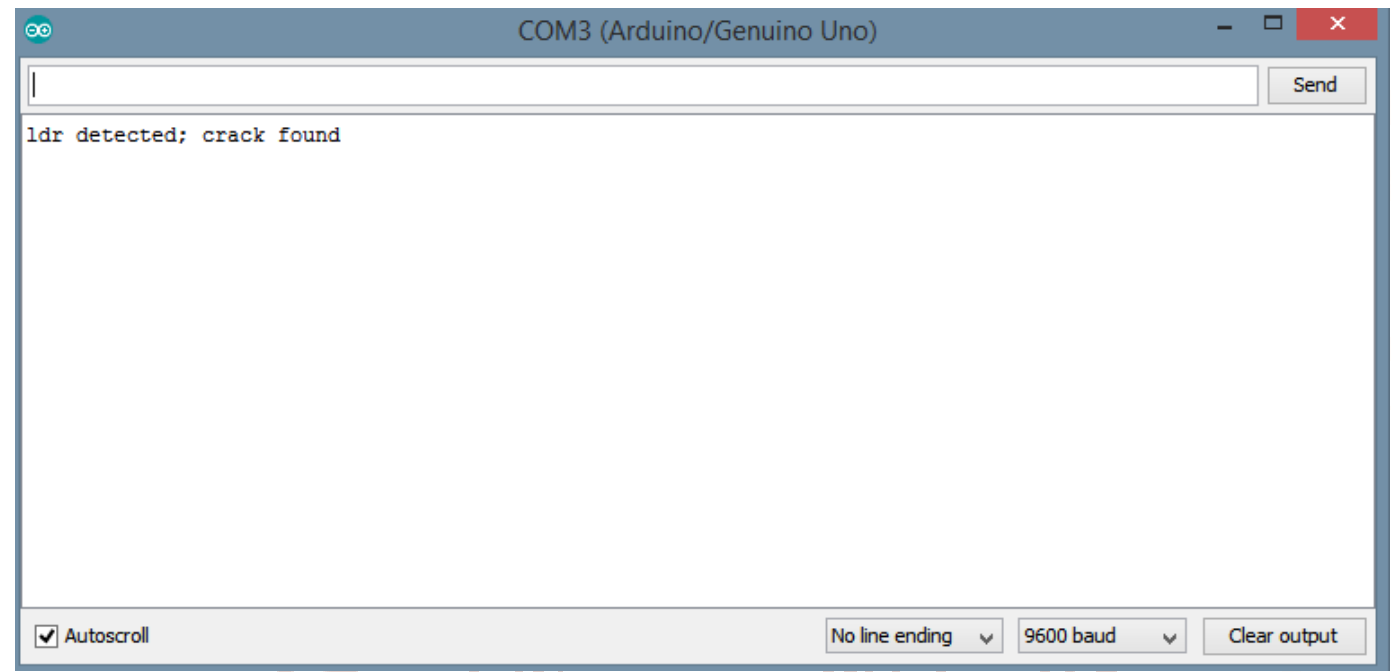

Figure 11: The output displayed in serial monitor when crack detected

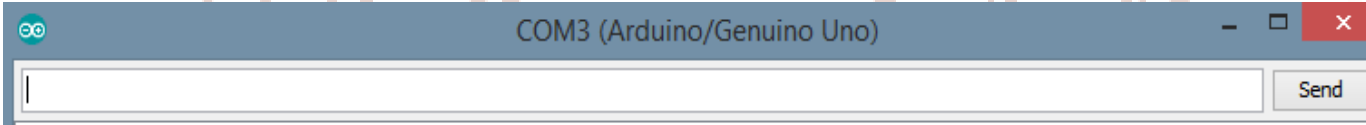

ldr not detected; crack not found

$\nabla$ Autoscroll

No line ending $\vee 9600$ baud

Clear output

Figure 12: The output displayed in serial monitor when crack not detected

$\infty \quad \operatorname{COM3}($ Arduino/Genuino Uno) $\quad-\quad \times \quad$ Send

ir detected; obstacle found

Figure 13: The output displayed in serial monitor when obstacle detected 


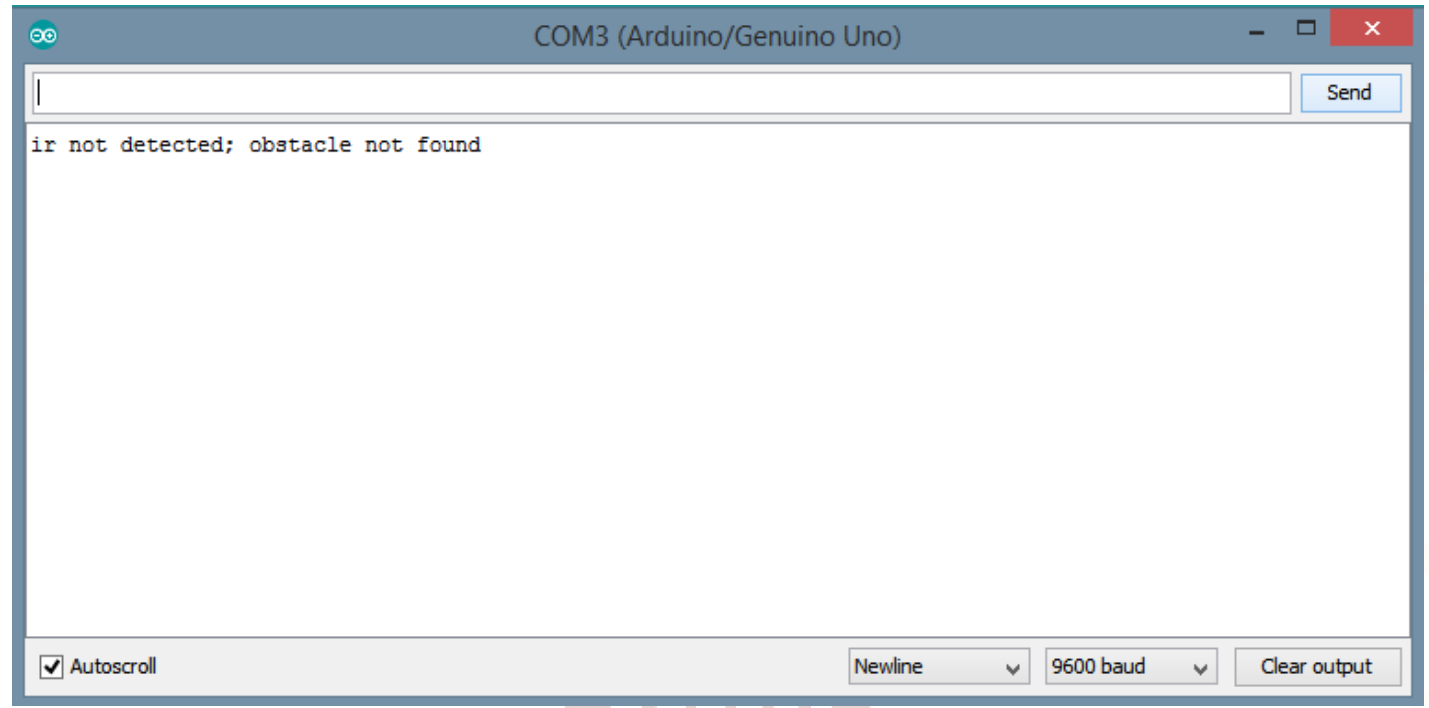

Figure 14: The output displayed in serial monitor when obstacle not detected

\section{CONCLUSION}

In this paper, pipeline inspection robot is proposed and implemented. A very important design goal is to find out the crack or object obstacle. The developed robot provides improved inspecting and increase detection ability.

\section{REFERENCES}

1. D. Jayakumar, R Jaganath, R Selvarasu, "Defect identification in pipelines using inspection robot", 2016 Online International Conference on Green Engineering and Technologies (IC-GET).

2. Lanyong Zhang, Yixuan Du, An Cao, "The Design Of Natural Gas Pipeline Inspection Robot System", 2015 IEEE International Conference On Information And Automation Lijiang, China.

3. Majid M Moghaddam, Alireza, Hadi, "Control and Guidance of a Pipe Inspection Crawler”, 2005
ISARC International Symposium on Automation and Robotics in Construction, Ferrara, Italy.

4. Hui Min Kim, HuiRyongYoo, Yong Woo Rho, GwanSoo Park, "Detection Method of Cracks by Using Magnetic Fields in Underground Pipeline", $201310^{\text {th }}$ International Conference on Ubiquitous Robots and Ambient Intelligence(URAI), Jeju, Korea.

5. Chung Wei Ou, Chin Jung Chao, "Design of an Adjustable Pipeline Inspection Robot with Three Belt Driven Mechanical Modules”, 2017 IEEE International Conference on Mechatronics and Automation, Takamatsu, Japan.

6. Samir Berjaoui, Rami Alkhatib, AbdallahElsheikh, MazenMorad, Mohamad O Diab, "Free Flowing Robot for Automatic Pipeline Leak Detection", 2015 IEEE. 